\title{
Further Evaluation of Swept Wing Icing Scaling with Maximum Combined Cross Section Ice Shape Profiles
}

\author{
Jen-Ching Tsao* \\ Ohio Aerospace Institute, Cleveland, OH 44142
}

This study reports results from recent icing scaling tests conducted in the NASA Glenn Icing Research Tunnel (IRT) using recommended scaling methods that were developed for swept wing icing applications. The aluminum test articles used in this study were NACA 0012 Adjustable Sweep Airfoil Models. The reference and scale airfoils have a 36 inch and 15 inch chord measured normal to the leading edge, and a 60 inch and 24 inch span respectively. Reference tests were run with airspeeds of 100, 140.3 and $150 \mathrm{knot}$ and MVD of 41.4, 44.4, 93 and $150 \mu \mathrm{m}$. All tests were set at $0^{\circ}$ angle of attack (AOA) and $30^{\circ}$ sweep angle. Results will be presented for stagnation freezing fractions ranging from 0.3 to 1.0 .

For non-dimensional reference \& scale ice shape comparison, a new post-scanning ice shape digitization procedure was applied to extract 2-D "hand-tracing like" ice shape profiles, i.e. the Maximum Combined Cross Section or MCCS, at selected span-wise locations from the high fidelity 3-D scanned ice shapes obtained in the IRT. Preliminary assessment of ice shape comparison with MCCS showed that good scaling was achieved for the test conditions by using the recommended scaling methods developed for swept wing icing.

\section{Nomenclature}

$A_{c} \quad=$ Accumulation parameter (Eq. (6)), dimensionless

$b=$ Relative heat factor (Eq. (11)), dimensionless

$c \quad=$ Airfoil chord, $\mathrm{cm}$

$c_{p} \quad=$ Specific heat of air, $\mathrm{cal} / \mathrm{g} \mathrm{K}$

$c_{p, w s}=$ Specific heat of water at the surface temperature, $\mathrm{cal} / \mathrm{g} \mathrm{K}$

$d \quad=$ Cylinder radius or twice the leading-edge radius of airfoil, $\mathrm{cm}$

$h_{c}=$ Convective heat-transfer coefficient, $\mathrm{cal} / \mathrm{s} \mathrm{m}^{2} \mathrm{~K}$

$h_{f} \quad=$ Water film thickness, $\mathrm{cm}$

$h_{G} \quad=$ Gas-phase mass-transfer coefficient, $\mathrm{g} / \mathrm{s} \mathrm{m}^{2}$

$K=\quad=$ Inertia parameter (Eq. (2)), dimensionless

$K_{0}=$ Modified inertia parameter (Eq. (1)), dimensionless

$L W C \quad=$ Cloud liquid-water content, $\mathrm{g} / \mathrm{m}^{3}$

$M V D=$ Water droplet median volume diameter, $\mu \mathrm{m}$

$n \quad=$ Local freezing fraction, dimensionless

$n_{0} \quad=$ Stagnation freezing fraction (Eq. (8)), dimensionless

$p \quad=$ Pressure, $\mathrm{Nt} / \mathrm{m}^{2}$

$p_{w} \quad=$ Vapor pressure of water in atmosphere, $\mathrm{Nt} / \mathrm{m}^{2}$

$p_{w w} \quad=$ Vapor pressure of water at the icing surface, $\mathrm{Nt} / \mathrm{m}^{2}$

$r \quad=$ Recovery factor, dimensionless

$\operatorname{Re}_{\delta} \quad=$ Reynolds number of water drop (Eq. (3)), dimensionless

$s \quad=$ Distance along airfoil surface measured from stagnation line, $\mathrm{cm}$

$t_{f} \quad=$ Freezing temperature, ${ }^{\circ} \mathrm{C}$

$t_{s} \quad=$ Surface temperature, ${ }^{\circ} \mathrm{C}$

$t \quad=$ Air temperature, ${ }^{\circ} \mathrm{C}$

$T=$ Absolute air temperature, $\mathrm{K}$

$V \quad=$ Air velocity, $\mathrm{kt}$

$W e_{L} \quad=$ Weber number based on model size and water properties (Eq. (13)), dimensionless

$\beta_{0} \quad=$ Collection efficiency at stagnation line (Eq. (5)), dimensionless

$\phi \quad=$ Droplet energy transfer parameter (Eq. (9)), ${ }^{\circ} \mathrm{C}$

\footnotetext{
${ }^{*}$ Principal Research Scientist, 22800 Cedar Point Road, Associate AIAA Fellow.
} 


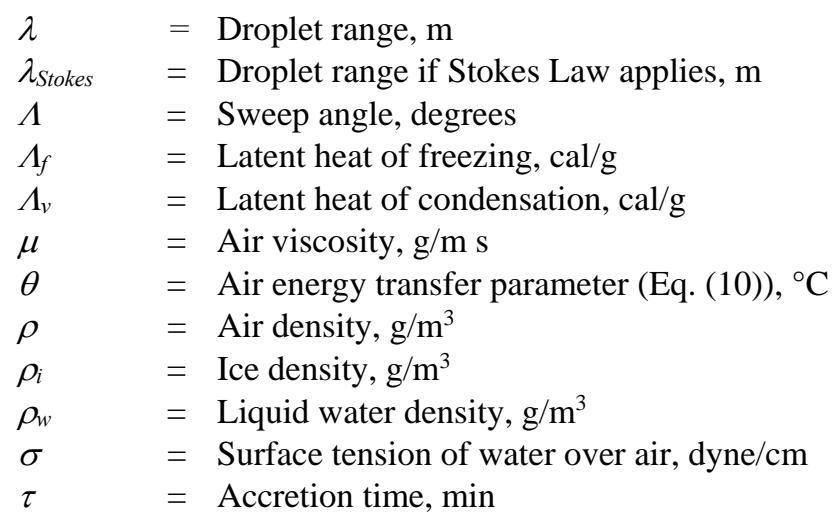

\begin{tabular}{|c|c|}
\hline \multicolumn{2}{|c|}{ Subscripts } \\
\hline$R$ & $=$ reference \\
\hline$S$ & $=$ scale \\
\hline & $=$ water film \\
\hline st & $=$ static \\
\hline tot & $=$ total \\
\hline$\Lambda$ & $=$ at sweep \\
\hline
\end{tabular}

\section{Introduction}

$\mathrm{T}$

The results presented here are part of an effort to develop appropriate scaling methods for swept wing ice accretion. Current icing scaling capability is still limited to simple geometries and two-dimensional wing sections. Modern applications such as swept wings, rotorcraft and turbofan engines require improved, validated methods of scaling ice shapes and iced performance for testing in ground-based facilities. While some progress has been made recently in these areas, additional work is required. Previously in 2011 Tsao and Lee ${ }^{1}$ have shown with a limited number of Appendix $C^{2}$ and SLD icing conditions on swept NACA 0012 models that a good match of main ice shape and ice feather regions was obtained when applying icing scaling methods on swept wing ice accretion. These acceptable scaling results could be achieved by matching the recommended similarity parameters $\beta 0, A_{c}, n_{0}$ and $W e_{L}$.

For swept wing icing scaling, the observations from previous work ${ }^{3,4,5,6}$ on ice accretion formations on swept wings have suggested that though there are distinctly different morphological features in final ice shapes observed on un-swept and swept wings, the fundamental ice accretion physics seems to be the same. Thus all the similarity parameters recommended for straight wing icing scaling should be applicable to swept wing icing provided appropriate modifications to the local collection efficiency and the convective heat transfer coefficient in the freezing fraction expression at the stagnation line due to model sweep angle were made. However it was evident from the ice shape comparison presented in Reference 1 that the traditional hand tracing method to document straight wing ice shapes was not sufficient to properly characterize the highly three dimensional ice shape features, e.g. the complete scallop tip, that are prevalent in swept wing ice accretion.

In 2014 Lee et al. ${ }^{7}$ reported a NASA icing research milestone in which the Icing Branch has successfully developed and validated a 3-D ice shape characterization methodology in NASA's icing Research Tunnel (IRT) using a laser-based scanner system and commercial image data analysis software. For this study, the 3-D scanner was used to characterize the ensuing ice shapes. For better visual examination of the reference and scale ice shape differences, a new procedure to "nondimensionalize" the 3-D ice shape from the scan was developed and the resultant 3-D scan ice shapes were presented later in the paper. In addition, various 2-D Maximum Combined Cross Section (MCCS) ice shape profiles of the 3-D scanned ice accretion were made to compare the reference and scale ice shapes at the icing tunnel centerline location to systematically evaluate the potential errors incurred from various possible techniques of acquiring those 2-D extraction of such complex 3-D ice shapes. In the present study, a limited number of reference and scale ice shape comparisons obtained from NACA 0012 airfoil models at $30^{\circ}$ sweep were made to evaluate how well the proposed scaling methods work in swept wing icing situations. 


\section{Similarity Parameters}

The similarity parameters used in this study were based on the work originally done by Ruff ${ }^{8}$. The scaling method involved matching scale and reference values of the key similarity parameters, $\beta_{0}, A_{c}, n_{0}$, and $W e_{L}$. The equations for the similarity parameters will be presented here without much discussion. Therefore, readers who are interested in the physical descriptions and detailed derivations of these parameters are referred to Anderson ${ }^{9}$ and Anderson and $\mathrm{TsaO}^{10}$ and the references given therein.

To maintain the droplet trajectory similitude, Langmuir and Blodgett ${ }^{11}$ introduced the modified inertia parameter, $K_{0}$, defined as

$$
K_{0}=\frac{1}{8}+\frac{\lambda}{\lambda_{\text {Stokes }}}\left(K-\frac{1}{8}\right)
$$

for $K>0.125$, to describe the inertia of droplets in an air stream flowing around a cylinder of radius $d$ positioned normal to the flow. In Eq. (1), $K$ is the inertia parameter,

$$
K=\frac{\rho_{w} M V D^{2} V}{18 d \mu} .
$$

Departing slightly from Langmuir and Blodgett in this study, $d$ represents twice the leading-edge radius of curvature for airfoils. For the NACA 0012 airfoil model, a leading-edge radius of $0.0158 c$ was used (see Abbott and von Doenhoff ${ }^{12}$ ), where $c$ is the airfoil chord. In Eq. (1), $\lambda / \lambda_{\text {Stokes }}$ is the droplet range parameter, defined as the ratio of actual droplet range to that if Stokes drag law for solid-spheres applied. It is a function only of the droplet Reynolds number, $R e \delta$.

$$
\operatorname{Re}_{\delta}=\frac{V M V D \rho}{\mu}
$$

This study uses a curve fit to Langmuir and Blodgett's tabulation of the range parameter as given in the following expression:

$$
\frac{\lambda}{\lambda \text { Stokes }}=\frac{1}{\left(0.8388+0.001483 R e_{\delta}+0.1847 \sqrt{R e_{\delta}}\right)}
$$

Of more practical interest than $K_{0}$ is the collection efficiency at the stagnation point, $\beta_{0}$, which was shown by Langmuir and Blodgett to be a function only of $K_{0}$,

$$
\beta_{0}=\frac{1.40\left(K_{0}-\frac{1}{8}\right)^{.84}}{1+1.40\left(K_{0}-\frac{1}{8}\right)^{.84}}
$$

It should be noted that the $\beta_{0}$ shown in Eq. (5) denotes the collection efficiency at the stagnation point for unswept NACA 0012 models. As for a NACA 0012 model at a given sweep angle $\Lambda\left(\leq 45^{\circ}\right)$, this study uses a curve fit from Tsao and Kreeger $^{13}$ to calculate the collection efficiency along the stagnation line, $\beta_{0, \Lambda}$,

$$
\beta_{0, \Lambda}=\beta_{0}(\cos \Lambda)
$$

Thus the droplet trajectory similarity is satisfied if $K_{0, S}=K_{0, R}$ and $\Lambda_{S}=\Lambda_{R}$ (so is $\left.\left(\beta_{0, A}\right)_{S}=\left(\beta_{0, A}\right)_{R}\right)$, and the scale drop size, i.e. scale $M V D$, is determined.

To ensure water-catch similarity, the accumulation parameter is introduced:

$$
A_{c}=\frac{L W C V \tau}{d \rho_{i}}
$$

If all the water impinging on the leading edge freezes at that location and the leading-edge collection efficiency is $100 \%, A_{c}$ directly becomes a measure of the normalized thickness of ice that will accrete. The scale accretion time 
can be found from $A_{c, S}=A_{c, R}$. When super-cooled water drops strike an aircraft surface, they may not freeze immediately on impact. The freezing fraction is the ratio of the amount of water that freezes in a specified region on the surface to the total amount of liquid water that reaches that region. Thus, local ice thickness depends on $\beta_{0, \Lambda} A_{c}$ and freezing fraction. Because each local ice thickness around the model defines the overall shape of the ice, the freezing fraction obviously has a major influence on ice shape. The freezing fraction is influenced mainly by the ambient temperature, the $L W C$ of the cloud and the aircraft velocity.

The rate at which the water freezes on a surface depends on the magnitude of local heat transfer imbalance. For glaze ice, it is known that the fraction of water that freezes is less than unity, and the motion of unfrozen surface water can have an effect on the resulting ice shape. Therefore, it is important to maintain surface energy and surfacewater dynamics similarities for glaze ice accretions. The freezing fraction is formally defined as the ratio of the amount of water that freezes at a given surface location to the total amount of water that impinges at that location. From Messinger's ${ }^{14}$ steady-state surface energy balance analysis, the freezing fraction at the stagnation point can be written as

$$
n_{0}=\frac{c_{p, w s}}{\Lambda_{f}}\left(\phi+\frac{\theta}{b}\right)
$$

The key terms in this formulation include $\phi$ and $\theta$, which have dimensions of temperature and relate to the water drop energy transfer and air energy transfer, and $b$, the relative heat factor, which was first introduced by Tribus, et. $a l^{15}$

$$
\begin{aligned}
& \varphi=t_{f}-t_{s t}-\frac{V^{2}}{2 c_{p, w s}} \\
& \theta=\left(t_{s}-t_{s t}-r \frac{V^{2}}{2 c_{p}}\right)+\frac{h_{G}}{h_{c}}\left(\frac{\frac{p_{w w}}{T_{s t}}-\frac{p_{t o t}}{T_{t o t}} \frac{p_{w}}{p_{s t}}}{\frac{1}{.622} \frac{p_{t o t}}{T_{t o t}}-\frac{p_{w w}}{T_{s t}}}\right) \Lambda_{v} \\
& b=\frac{L W C V \beta_{0} c_{p, w s}}{h_{c}}
\end{aligned}
$$

Equation (10) from Ruff ${ }^{8}$ has included compressibility effects. Various incompressible forms of $\theta$ have also been used by Charpin and Fasso ${ }^{16}$ and others; however, the differences are not significant mainly due to the fact that, for most icing conditions, the Mach number is relatively low.

As for the sweep angle effect on the convective heat transfer along the stagnation line of the NACA 0012 wing section, it was shown by Reshotko and Beckwith ${ }^{17}$ that for incompressible flows the ratio of swept to normal convective heat transfer coefficient became

$$
h_{c, \Lambda}=h_{c}(\cos \Lambda)^{\frac{1}{2}}
$$

It should be noted that the $h_{c}$ shown above represents the convective heat-transfer coefficient at the stagnation point for unswept NACA 0012 models and for brevity its expression can be found in Reference 9 for interested readers. Since for most icing conditions the Mach number is relatively low Eq. (12) is used. Some experimental evaluations of this expression for calculating the freezing fraction on a swept wing are made in this study.

In 1988 Bilanin ${ }^{18}$ presented a Buckingham- $\pi$ analysis in which he concluded that surface-water phenomena had to be included in icing scaling methods. Olsen and Walker ${ }^{19}$ and Hansman et al ${ }^{20,21,22}$ studied surface effects and surface water during ice accretion, presenting additional evidence that these were important phenomena to consider in ice accretion. From the close-up photographs of these research studies, it was observed that for glaze ice accretion unfrozen water on the ice surface tended to coalesce to form beads. These beads sometimes were swept downstream and sometimes froze in place. Bilanin ${ }^{18,23}$ also argued that drop splashing on impact might affect the shape of the ice accreted. 
Hansman and Turnock ${ }^{20}$ found that when a surfactant was added to the icing spray water, the ice shape appearance and shape changed significantly, with the glaze horns moving toward the leading edge. Clearly, then, surface tension, and by implication, surface phenomena, have a significant role in the physics of ice accretion.

In 2003 Anderson and $\mathrm{Tsao}^{24}$ had provided experimental evidence from past studies to show that a similarity parameter dependent on the ratio $V^{x} \mathcal{C}^{y} / \sigma^{z}$ must be included in scaling methodology to account for surface-water dynamics effect in glaze ice accretions, although the powers $x, y$ and $z$ are not yet determined. The length may not be the chord itself but rather some physical characteristic $L$ related to the chord; for example, the water-film thickness. Likewise, the velocity could also be of the water-film that is related to $V$. Thus a Weber number based on $L$ and $V$

$$
W e_{L}=\frac{V^{2} L \rho_{w}}{\sigma}
$$

has been suggested as a potential additional similarity parameter to supplement Ruff's basic scaling method. Studies by Bartlett ${ }^{25,26}$ and Oleskiw, et. al. ${ }^{27}$ found no measurable effect of pressure on ice shape. These observations suggest that water density is a better choice than air density for eq. (13). In this study the $W e_{L}$ is based on the twice the nose radius of the airfoil:

$$
W e_{L}=\frac{V^{2} d \rho_{w}}{\sigma}
$$

with the understanding that $L \propto d$. The scale velocity found from matching $W e_{L, S}=W e_{L, R}$ is

$$
V_{S}=V_{R}\left(\frac{d_{R}}{d_{S}}\right)^{1 / 2}
$$

\section{Test Description}

In this section, some test related information on the latest IRT's cloud calibration, swept wing models used, procedure to run a test and document the final ice shape with a 3-D laser scanning system were given first. Then some discussion on the creation and evaluation of MCCS from a 3-D scan of the ice and a standard uncertainty analysis of the average icing condition were provided.

\section{A. Facility, Model and Procedures}

The IRT is a closed-loop, refrigerated, sea level tunnel with a $1.8 \mathrm{~m}$ by $2.7 \mathrm{~m}$ rectangular test section. The icing cloud is generated by operating 10 spray bars, a configuration in use since 1998. The IRT cloud calibrations for both Appendix C and SLD conditions used for these tests were released in the May of $2015^{28}$. The $L W C$ and $M V D$ measurements were made using methods reported previously. ${ }^{29}$ The $L W C$ measurements were made using the Multi-Element water content sensor (commonly known as Multi-Wire sensor) from Science Engineering Associates, Inc. (SEA) as reported recently ${ }^{30}$. However, there was some correction made to Standard and Mod1 nozzle $L W C$ values due to new 3-D Etot corrections from Rigby, et. al. ${ }^{31}$. In addition, SLD reference tests are constrained to these specific conditions or preferably chosen within the calibrated envelope.

The aluminum test articles used in this study were NACA 0012 Adjustable Sweep Airfoil Models. The reference and scale airfoils have a $0.914 \mathrm{~m}$ (36 inch) and $0.381 \mathrm{~m}$ (15 inch) chord measured normal to the leading edge, and a $1.524 \mathrm{~m}$ (60 inch) and $0.609 \mathrm{~m}$ (24 inch) span respectively. The reference model was mounted in the tunnel on the floor at $30^{\circ}$ sweep angle position (see Fig. 1). The scale model was mounted in the tunnel on a stand with a small extension that allows pivoting of the airfoil to sweep angle of $30^{\circ}$ in the mid-span of the test section where the cloud uniformity is the best (see Fig. 2). Black horizontal lines at the leading edge were drawn on the surface of the airfoil at the tunnel vertical center to help identify sites on the model for close-up photographs of feather structure details.

In preparing for a test, the temperature and airspeed in the test section and the air and water pressures on the spray manifolds were set. When these conditions had stabilized and the model was also properly cold soaked, the spray nozzle valves were opened to initiate the spray. The spray was timed for the required duration, and then turned off. Immediately after the completion of a glaze icing spray, the fan was brought down nearly to a full stop to maintain a wind tunnel airspeed of 5-10 knots while keeping the air static temperature around $-4{ }^{\circ} \mathrm{C}$ to avoid melting of the glaze ice shape. The researchers entered the test section to first document the ice shape with a hand-held digital camera. The iced airfoil was further painted using an alcohol-based titanium dioxide paint. A commercially available articulated-arm, the ROMER Absolute Arm, 3-D laser scanning system was placed in the IRT test section up- 
stream of the airfoil model. A detailed 3-D ice shape scan was then made of the front 10-15\% chord of the iced airfoil leading-edge region (in the stream-wise direction). Each scan was 6-in wide roughly (in the span-wise direction) and was performed at the mid-span location of the model (i.e. 36 in above the floor).

The ice shapes so recorded were further digitally manipulated using the 2-D cross section cut feature in Geomagic Control ${ }^{32}$ and the output feature of 2-D outline control point coordinates from Rhinoceros ${ }^{33}$ and its scripting functionality, Rhinoscript. The results presented in this study were from two IRT test entries in October 31 - November 4 and December 8-14, 2016.

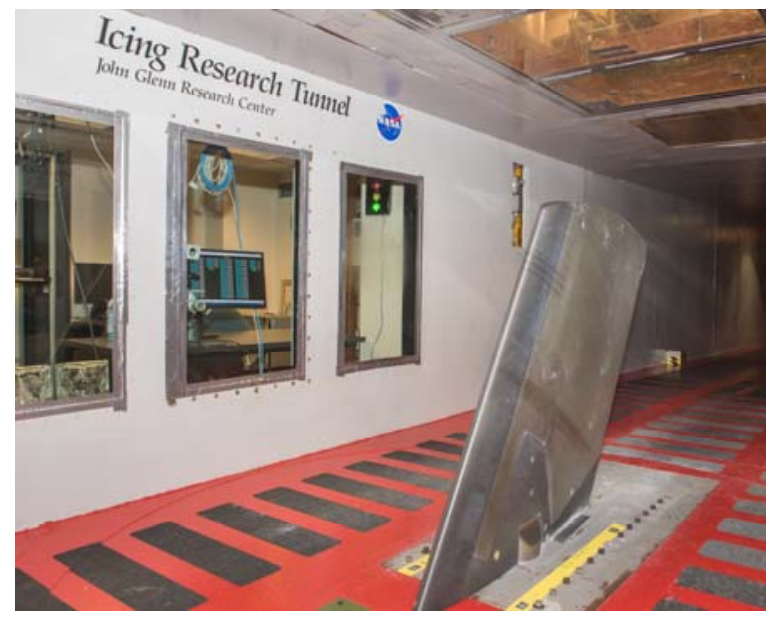

Figure 1. 36-in-chord reference model.

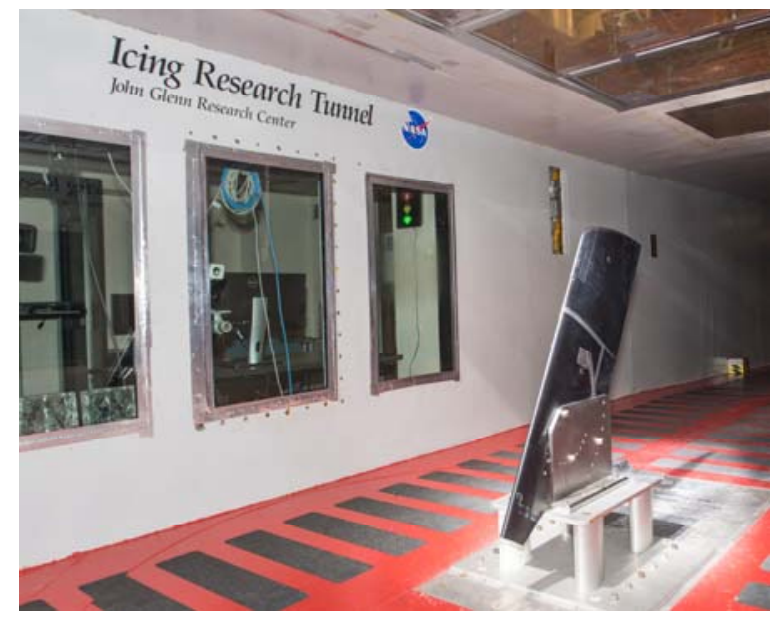

Figure 2. 15-in-chord scale model.

\section{B. The Maximum Combined Cross Section (MCCS)}

The ice shape results shown in this paper consist of 3-D scan ice shapes, 2-D section cuts and digital photographs to better document the general 3-D morphological features of those ice shapes. Many of the ice accretions observed during the IRT test entries were highly three dimensional, such that any type of 2-D description is simply not adequate. However icing simulation tools typically provide 2-D ice-shape cross-sections, results of this type are still desirable and needed for comparison. The approach that was evaluated in this study was to take $(5,10,15)$ section cuts through the 3-D scan of the ice accretion perpendicular to the reference model leading edge as shown in Figure 3. These section cuts were taken at a fixed spacing of 0.05 inch covering $0.25,0.5$ and 0.75 inch of ice shape along the leading edge above the model centerline, 36 inch above the floor. Those section cuts were projected onto a single plane and the maximum outline was obtained. The resulting Maximum Combined Cross Section ${ }^{34}$, or MCCS, represents the outermost extent of the ice accretion over the prescribed span-wise segment length. Some evaluations of the ice segment length effect on the resulting MCCS were made and the final set of reference and scale ice shape comparison will be provided in the Results section with MCCS obtained from the 0.25 inch ice segment length.
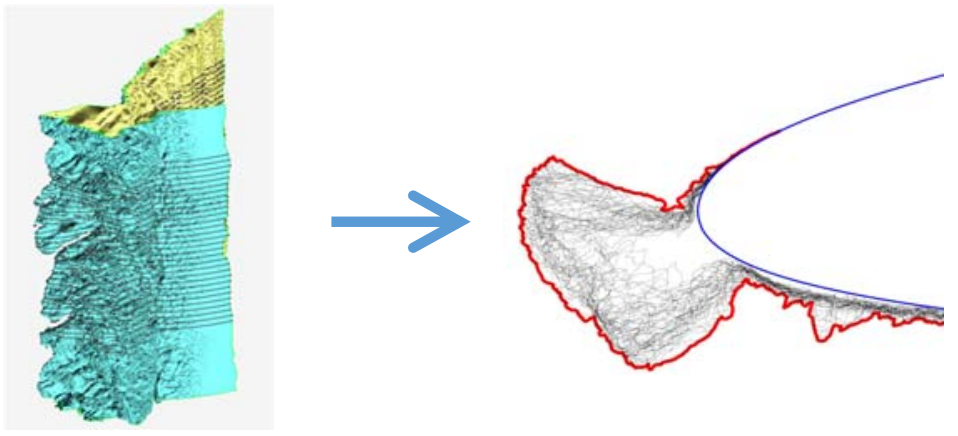

Figure 3. Schematics of processes to obtain the Maximum Combined Cross Section (MCCS) of a 3-D scan ice shape of prescribed segment length (Note: the images shown here are duplicates from Ref. 34 Figure 6). 


\section{Uncertainty Analysis}

Estimates of the uncertainty in the reported average conditions were made by considering inherent errors of instruments, temporal fluctuation and spatial variation of the instrument readings in the test section, and uncertainty in tunnel calibration of $M V D$ and $L W C$. Recorded air temperature was believed to be accurate to $\pm 0.5^{\circ} \mathrm{C}$, and the uncertainty in air velocity were estimated to be $\pm 1 \mathrm{~m} / \mathrm{s}$. For Appendix C conditions the net uncertainty in $M V D$ was estimated at $\pm 12 \%$. For SLD conditions it may have been as much as $\pm 20 \%$. These uncertainties are not referenced to an absolute value of $M V D$, which is unknown. Repeatability and scatter in the $L W C$ calibration data suggests the uncertainty is about $\pm 12 \%$ for both Appendix C and SLD conditions.

The test-parameter uncertainties were used to estimate the following uncertainties in the similarity parameters for the Appendix C tests: $3 \%$ in $\beta_{0}, 12 \%$ in $A_{c}, 13 \%$ in $n_{0}$ and $2 \%$ in $W e_{L}$. For the SLD tests the uncertainties were: $4 \%$ in $\beta_{0}, 12 \%$ in $A_{c}, 12 \%$ in $n_{0}$ and $4 \%$ in $W e_{L}$.

\section{Results}

Evaluation of swept wing icing scaling methods with MCCS ice shape profile comparison from two recent fiveday IRT tests are presented here. The reference cases include $M V D s$ of 41.4, 44.4, 93 and $150 \mu \mathrm{m}$, and airspeeds of 100, 140.3 and 150 knot. For the baseline case of $V=100$ and 150 knot and $M V D=41.4$ and $93 \mu \mathrm{m}$, air temperatures were varied to provide stagnation point freezing fraction $\left(n_{0}\right)$ of 0.30 to 0.68 which covers both the complete and incomplete scallop ice formation regimes. Repeat runs were performed for some reference and scale conditions with the purpose of acquiring sufficient ice shapes to assess the repeatability of the ice shape. Furthermore, three reference conditions were chosen for the freezing fraction sweep (i.e. temperature sweep) to obtain representative ice shape data. Notice that in the following subsections the air temperature effect on both the MCCS ice shape profiles and the 3-D ice shapes are given first and then the evaluation of swept wing icing scaling methods with MCCS ice shape profile and 3-D scan comparison are presented.

\section{A. Effect of Air Temperature on MCCS Ice Shape Profile}

From previous ice shape studies ${ }^{1-5,8-9}$ on both straight and swept NACA 0012 wing section models of different chord sizes, it was well known that the 2-D hand-tracing of resultant ice shapes will vary with the corresponding air temperature (i.e. the stagnation point freezing fraction) regardless of whether the ice accretion was formed on a straight wing or a swept wing section suggesting that the underlying fundamental ice accretion physics is basically the same. So it is necessary for one to ascertain at first that this 2-D MCCS ice shape profile from a 3-D scan will exhibit the similar trend of ice shape variation with air temperature. This fundamental icing physics feature is used to determine the optimal ice length segment for obtaining the MCCS as described in the previous section III-B.

The air temperature effect on 2-D MCCS ice shape profile is shown in Figures 4 and 5. The tests were conducted in the IRT using the 36-in-chord NACA 0012 swept wing model at airspeeds of 100 and 150 knots. In both figures,
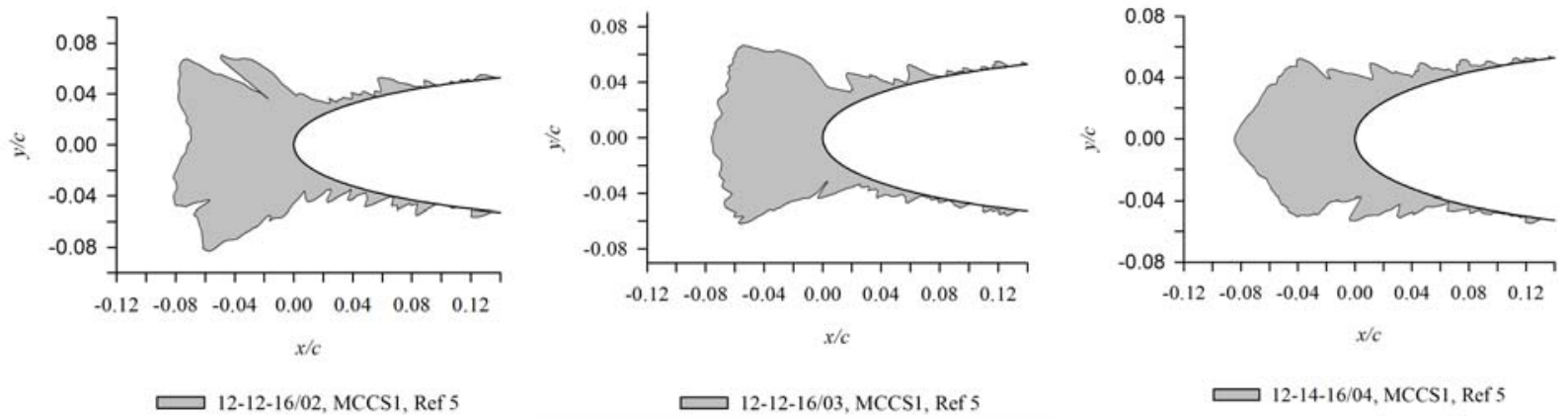

\begin{tabular}{cccccccccc} 
Date/Run & $\begin{array}{c}c, \\
\text { in }\end{array}$ & $\begin{array}{r}\Lambda, \\
{ }^{2}\end{array}$ & $\begin{array}{c}t_{\text {tot }}, \\
{ }^{\circ} \mathrm{C}\end{array}$ & $\begin{array}{c}V, \\
\mathrm{kt}\end{array}$ & $\begin{array}{c}M V D, \\
\mu \mathrm{m}\end{array}$ & $\begin{array}{c}L W C, \\
\mathrm{~g} / \mathrm{m}^{3}\end{array}$ & $\begin{array}{c}\tau, \\
\mathrm{min}\end{array}$ & $\beta_{0} A_{c}$ & $n_{0}$ \\
\hline $12-12-16 / 02$ & 36 & 30 & -5.9 & 100.0 & 93.0 & 0.66 & 52.2 & 3.17 & 0.38 \\
$12-12-16 / 03$ & 36 & 30 & -10.0 & 100.0 & 93.0 & 0.66 & 52.2 & 3.17 & 0.60 \\
$12-14-16 / 04$ & 36 & 30 & -18.1 & 100.0 & 93.0 & 0.66 & 52.2 & 3.17 & 1.00
\end{tabular}

Figure 4. Effect of air temperature on MCCS ice shape profile. Swept NACA 0012 model at $30^{\circ}$ sweep. $\mathrm{V}=100 \mathrm{kt}$. 

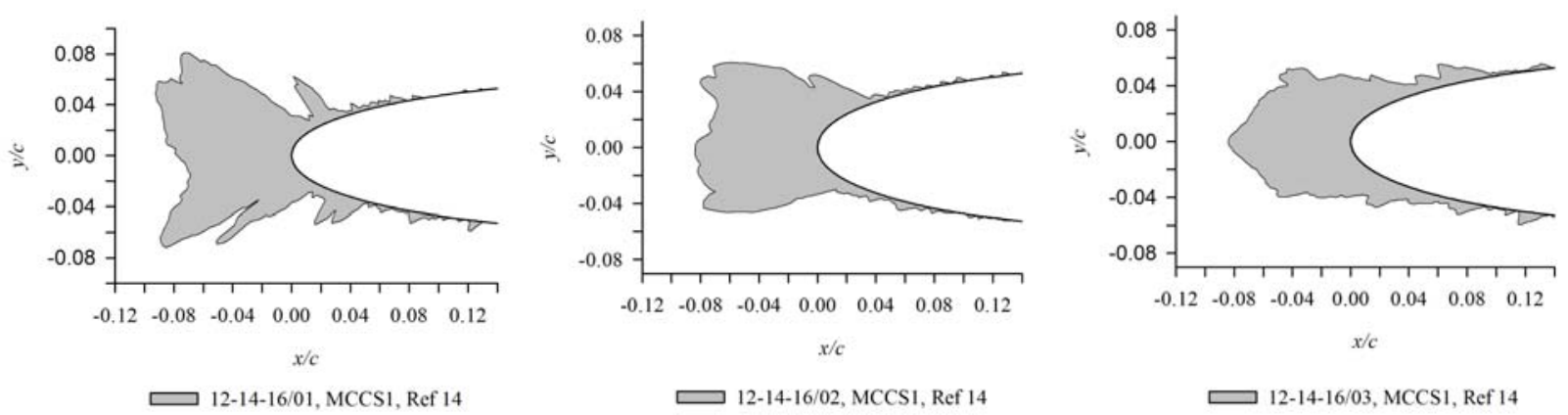

\begin{tabular}{rccccccccc} 
Date/Run & $\begin{array}{c}c, \\
\text { in }\end{array}$ & $\begin{array}{r}\Lambda, \\
{ }^{2}\end{array}$ & $\begin{array}{c}t_{\text {tot }}, \\
{ }^{\circ} \mathrm{C}\end{array}$ & $\begin{array}{c}V, \\
\mathrm{kt}\end{array}$ & $\begin{array}{c}M V D, \\
\mu \mathrm{m}\end{array}$ & $\begin{array}{r}L W C, \\
\mathrm{~g} / \mathrm{m}^{3}\end{array}$ & $\begin{array}{c}\tau, \\
\min \end{array}$ & $\beta_{0} A_{c}$ & $n_{0}$ \\
\hline $12-14-16 / 01$ & 36 & 30 & -5.0 & 150.0 & 93.0 & 0.5 & 45.2 & 3.17 & 0.38 \\
$12-14-16 / 02$ & 36 & 30 & -9.0 & 150.0 & 93.0 & 0.5 & 45.2 & 3.17 & 0.60 \\
$12-14-16 / 03$ & 36 & 30 & -16.8 & 150.0 & 93.0 & 0.5 & 45.2 & 3.17 & 1.00
\end{tabular}

Figure 5. Effect of Air Temperature on MCCS ice shape Profile. Swept NACA 0012 model at $30^{\circ}$ sweep. $\mathrm{V}=150 \mathrm{kt}$.

the MCCS profiles all started from a typical glaze ice shape with horns at warmer air temperature (i.e. lower $n_{0}$ ). With each incremental decrease in temperature (i.e. consequent increase in $n_{0}$ ) the ice horns moved forward and the leading edge ice thickness increased. This fundamental icing physics feature is indeed correctly captured by this newly developed MCCS ice shape profiles.

\section{B. Effect of Air Temperature on 3-D Ice Shape}

Figures 6 and 7 display the corresponding 3-D scan images of swept wing ice shapes variation at airspeeds of 100 and 150 knots. A large complete ice scallop structure was formed at $n_{0}=0.38$, an incomplete ice scallop structure was formed at $n_{0}=0.60$ and a rime ice was formed at $n_{0}=1.0$. It should be noted that although the laser scan images look fairly realistic the laser scanning still cannot capture all the 3-D features of ice scallops and larger SLD feathers immediately aft of the main ice shape due to its inherent limitation from the line of sight based technology.
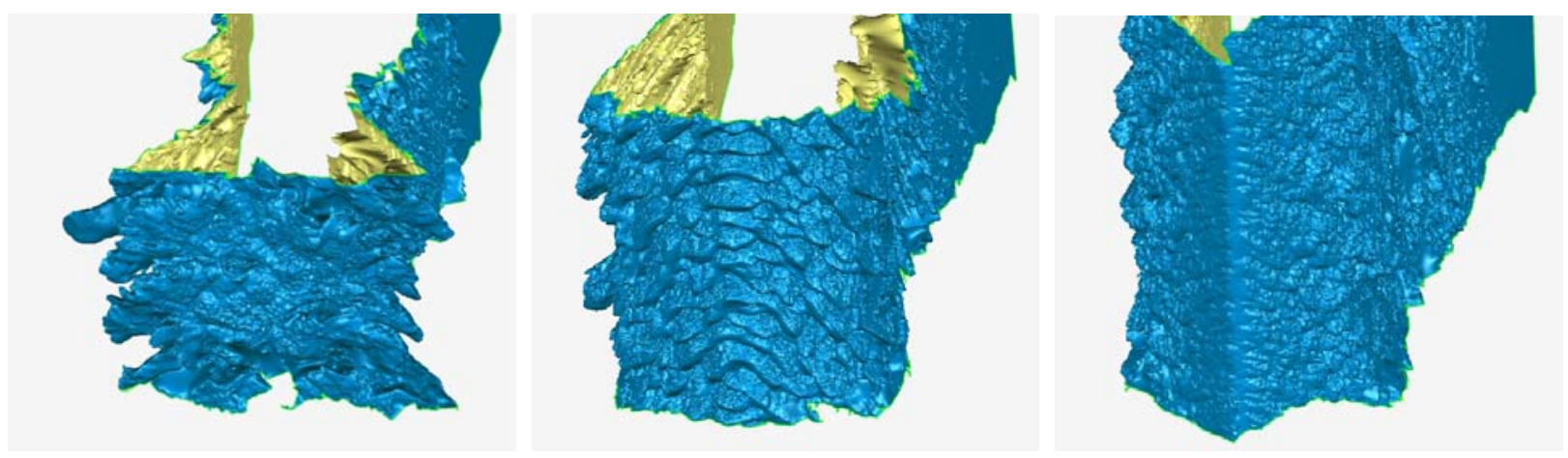

\begin{tabular}{cccccccccc} 
Date/Run & $\begin{array}{c}c, \\
\text { in }\end{array}$ & $\begin{array}{r}\Lambda, \\
{ }^{2}\end{array}$ & $\begin{array}{c}t_{\text {tot }}, \\
{ }^{\circ} \mathrm{C}\end{array}$ & $\begin{array}{c}V, \\
\mathrm{kt}\end{array}$ & $\begin{array}{c}M V D, \\
\mu \mathrm{m}\end{array}$ & $\begin{array}{c}L W C, \\
\mathrm{~g} / \mathrm{m}^{3}\end{array}$ & $\begin{array}{r}\tau, \\
\mathrm{min}\end{array}$ & $\beta_{0} A_{c}$ & $n_{0}$ \\
\hline $12-12-16 / 02(\mathrm{~L})$ & 36 & 30 & -5.9 & 100.0 & 93.0 & 0.66 & 52.2 & 3.17 & 0.38 \\
$12-12-16 / 03(\mathrm{M})$ & 36 & 30 & -10.0 & 100.0 & 93.0 & 0.66 & 52.2 & 3.17 & 0.60 \\
$12-14-16 / 04(\mathrm{R})$ & 36 & 30 & -18.1 & 100.0 & 93.0 & 0.66 & 52.2 & 3.17 & 1.00
\end{tabular}

Figure 6. The 3-D scan images of the swept wing ice accretion shown in Fig. 4 include a complete scallop, an incomplete scallop and a rime ice.

8

American Institute of Aeronautics and Astronautics 

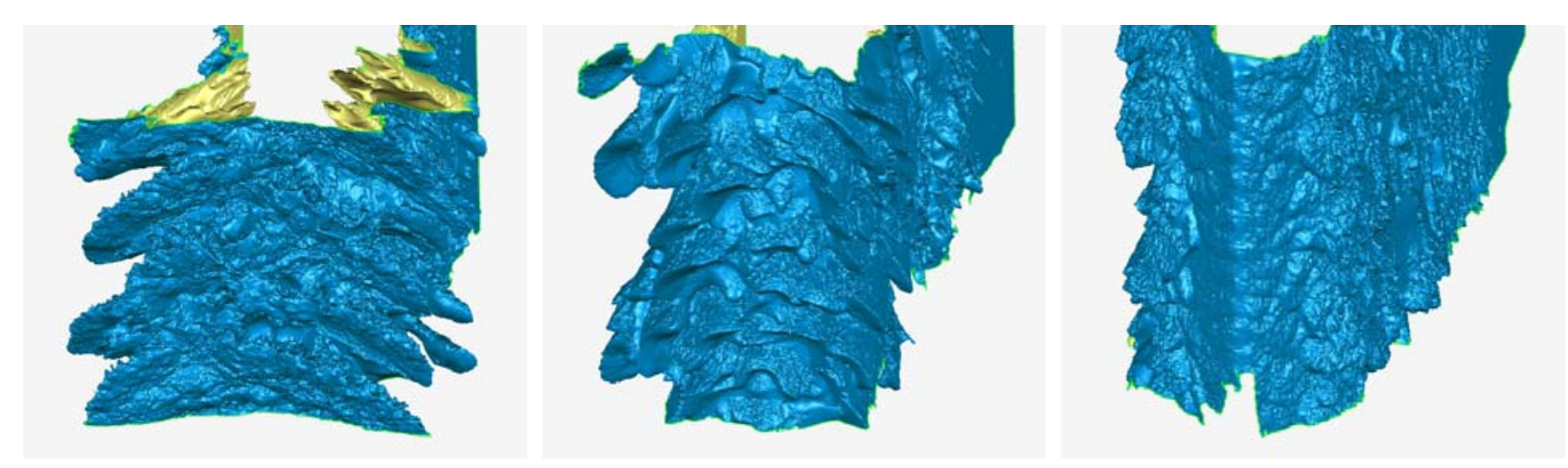

\begin{tabular}{cccccccccc} 
Date/Run & $\begin{array}{c}c, \\
\text { in }\end{array}$ & $\begin{array}{c}\Lambda, \\
{ }^{\circ}\end{array}$ & $\begin{array}{c}t_{\text {tot }}, \\
{ }^{\circ} \mathrm{C}\end{array}$ & $\begin{array}{c}V, \\
\mathrm{kt}\end{array}$ & $\begin{array}{c}M V D, \\
\mu \mathrm{m}\end{array}$ & $\begin{array}{c}L W C, \\
\mathrm{~g} / \mathrm{m}^{3}\end{array}$ & $\begin{array}{c}\tau, \\
\min \end{array}$ & $\beta_{0} A_{c}$ & $n_{0}$ \\
\hline $12-14-16 / 01(\mathrm{~L})$ & 36 & 30 & -5.0 & 150.0 & 93.0 & 0.5 & 45.2 & 3.17 & 0.38 \\
$12-14-16 / 02(\mathrm{M})$ & 36 & 30 & -9.0 & 150.0 & 93.0 & 0.5 & 45.2 & 3.17 & 0.60 \\
$12-14-16 / 03(\mathrm{R})$ & 36 & 30 & -16.8 & 150.0 & 93.0 & 0.5 & 45.2 & 3.17 & 1.00
\end{tabular}

Figure 7. The 3-D scan images of the swept wing ice accretion shown in Fig. 5 include a complete scallop, an incomplete scallop and a rime ice.

\section{Evaluation of Swept Wing Icing Scaling with MCCS Ice Shape Profile and 3-D Scan}

Figures 8-10 present the non-dimensional reference and scale 2-D MCCS ice shape profiles and the corresponding 3-D ice shape scan images obtained from the constant $W e_{L}$ method at reference velocities of 150 knots for stagnation point freezing fraction $n_{0}$ of $0.38,0.6$ and 1.0 respectively. For each figure, the reference MCCS ice shape is shown shaded, while a solid line indicates the scale MCCS ice shape. The table below each figure gives the test conditions and similarity parameters for each group of reference and scale tests. The parameters in the tables were calculated from those average conditions. In addition the non-dimensional reference and scale 3-D scan images are provided within each figure right below the MCCS ice shape profiles to represent these two original 3-D ice accretion structures. For better visual comparison of 3-D scan images, future tests will have to scan the same number of scallops on both reference and scale models in the span-wise direction.

In Figure 8, it is shown that for the 2-D MCCS ice shape comparison at $n_{0}$ of 0.38 , the scale ice shape gave a good match of the reference main ice shape and feather region, even including smaller feathers further aft on the surface. Also it was noticed from the 3-D scan comparison that there were roughly the same number of complete ice scallops formed over the same non-dimensional span-wise distance. For this case shown in Figure 8 where the $n_{0}$ is 0.38 and the airspeed is 150 knots, there are roughly three complete ice scallops per one non-dimensional scallop width. This preliminary finding further expands our current understanding of ice accretion physics that the stagnation point freezing fraction $n_{0}$ is a key parameter to the ice scallop formation but now there is a new set of ice shape feature data to suggest that it can also affect the number of scallops to be formed per unit non-dimensional length on a given model setting. Additional tests are needed in order to establish the basic correlational function to simulate this potentially important 3-D swept wing ice shape feature.

Figure 9 shows the reference and scale MCCS ice shape comparison for this large reference drop size of $93 \mu \mathrm{m}$ at $n_{0}$ of 0.60 . The scale ice shape was able to duplicate the reference main ice shape and feather region quite well but the leading edge ice thickness of scale ice shape was about $10 \%$ larger than the reference ice shape. For IRT SLD clouds, the test parameter uncertainties for $A_{c}$ and $n_{0}$ are both $12 \%$. Therefore this ice shape difference would be considered within the facility ice shape repeatability limit. As for the 3-D scan comparison, the ice scallop gaps were closing in fast as $n_{0}$ was increased from 0.38 to 0.60 and as a result they became incomplete ice scallop structures.

Finally, Figure 10 shows the reference and scale MCCS ice shape comparison at rime condition (i.e. $n_{0}=1.0$ ). The scale MCCS ice shape had a nearly rime ice shape profile but it still gave a very good match of the reference rime ice shape. From the 3-D scan comparison, it was noted that the scale ice structure frontal surface area seems to still have some larger ice scallop tips not fully closed up to the ice surface to form a smooth rime ice shape as one normally would expect in rime condition. This is most likely because the span-wise $L W C$ distribution of this SLD cloud is not as uniform in span-wise direction. If this is the case, cloud uniformity at the test section of an icing wind tunnel over its entire icing simulation envelope, including both Appendix C and SLD icing clouds, could be critical 
in order to appropriately evaluate any potential icing scaling method for modern 3-D swept wing icing applications. Regardless, these preliminary results show the scaling methods are effective. Additionally, the MCCS ice shape profiles and non-dimensional 3-D scan ice shape comparison evaluated in this study require further evaluation over wider airflow and icing cloud conditions as well as different model sizes to assess its applicability for swept-wing icing scaling analysis.

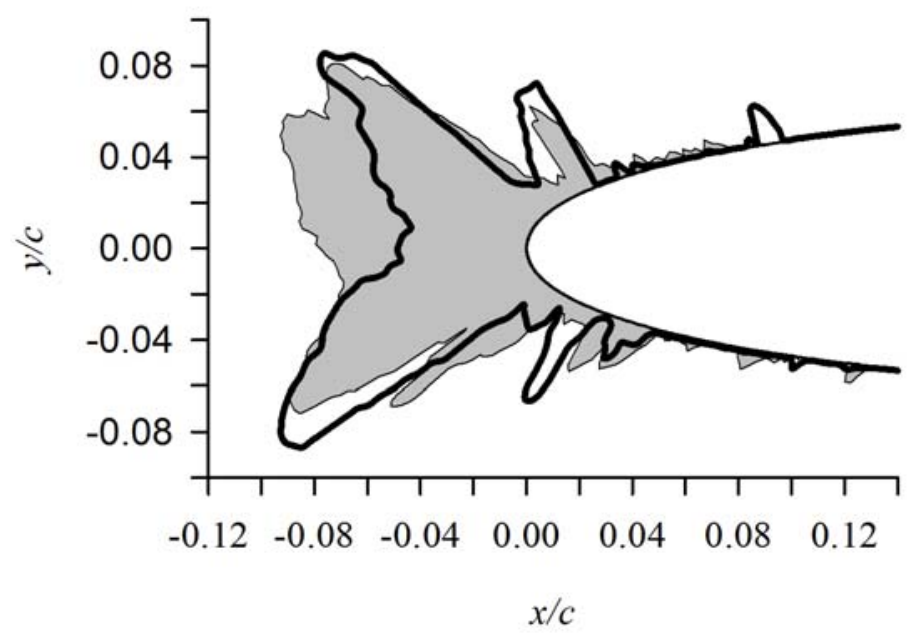

$\square$ 12-14-16/01, MCCS1, Ref 14

- 11-03-16/02, MCCS1, CWeL 14

$12-14-16 / 01$

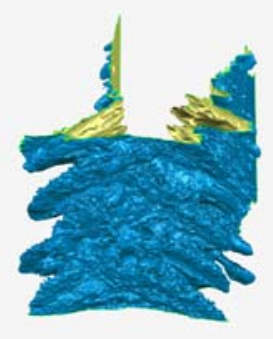

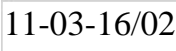

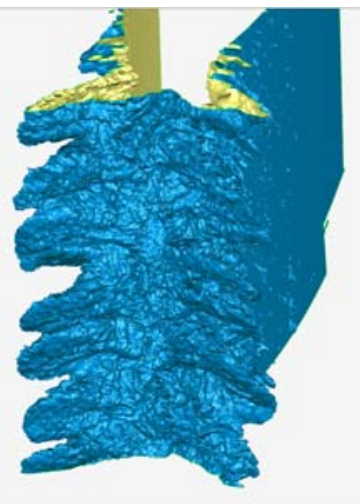

\begin{tabular}{ccccc}
$L W C$, & $\begin{array}{c}\tau, \\
\mathrm{g} / \mathrm{m}^{3}\end{array}$ & $\begin{array}{c}\mathrm{min} \\
A_{0} A_{c}\end{array}$ & $n_{0}$ & $\begin{array}{c}W e_{L}, \\
10^{6}\end{array}$ \\
\hline 0.50 & 45.2 & 3.17 & 0.38 & 2.65 \\
0.45 & 13.5 & 3.16 & 0.38 & 2.65
\end{tabular}

Figure 8. Reference and scale MCCS ice shape comparison. NACA 0012 models at $30^{\circ}$ sweep, $V_{R}=150 \mathrm{kt}$; Complete ice scallops were formed at $n_{0}=0.38$. 


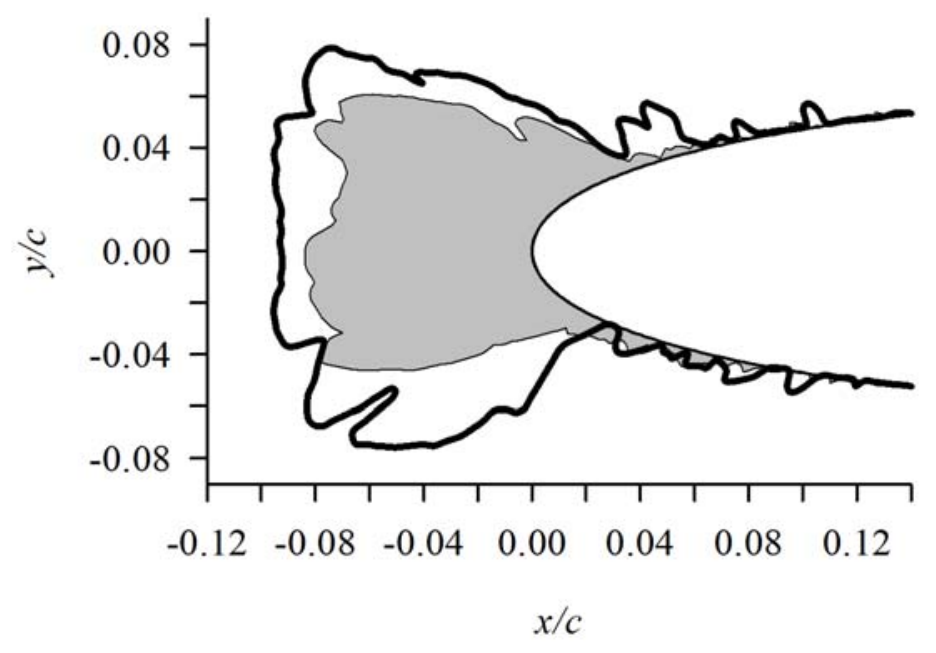

$\square$ 12-14-16/02, MCCS1, Ref 14

- 12-09-16/04, MCCS1, CWeL 14

$12-14-16 / 02$

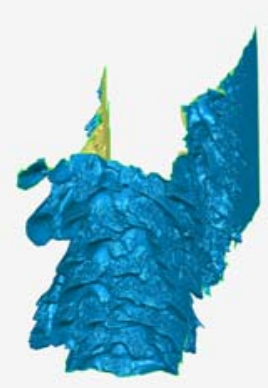

$12-09-16 / 04$

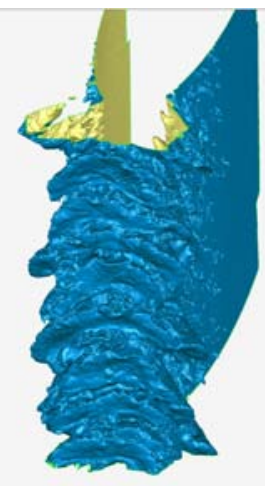

\begin{tabular}{ccrcccccccc}
\multirow{2}{*}{ Date/Run } & $\begin{array}{c}c, \\
\text { in }\end{array}$ & $\begin{array}{r}\Lambda, \\
{ }^{2}\end{array}$ & $\begin{array}{c}t_{\text {tot }}, \\
{ }^{\circ} \mathrm{C}\end{array}$ & $\begin{array}{c}V, \\
\mathrm{kt}\end{array}$ & $\begin{array}{c}M V D, \\
\mu \mathrm{m}\end{array}$ & $\begin{array}{c}L W C, \\
\mathrm{~g} / \mathrm{m}^{3}\end{array}$ & $\begin{array}{r}\tau, \\
\mathrm{min}\end{array}$ & $\beta_{0} A_{c}$ & $n_{0}$ & $\begin{array}{c}W e_{L}, \\
10^{6}\end{array}$ \\
\hline $12-14-16 / 02$ & 36 & 30 & -9.0 & 150.0 & 93.0 & 0.50 & 45.2 & 3.17 & 0.60 & 2.65 \\
$12-09-16 / 04$ & 15 & 30 & -5.2 & 232.4 & 44.2 & 0.45 & 13.5 & 3.16 & 0.60 & 2.65
\end{tabular}

Figure 9. Reference and scale MCCS ice shape comparison. NACA 0012 models at $30^{\circ}$ sweep. $V_{R}=150 \mathrm{kt}$; Incomplete ice scallops were formed at $n_{0}=\mathbf{0 . 6 0}$. 


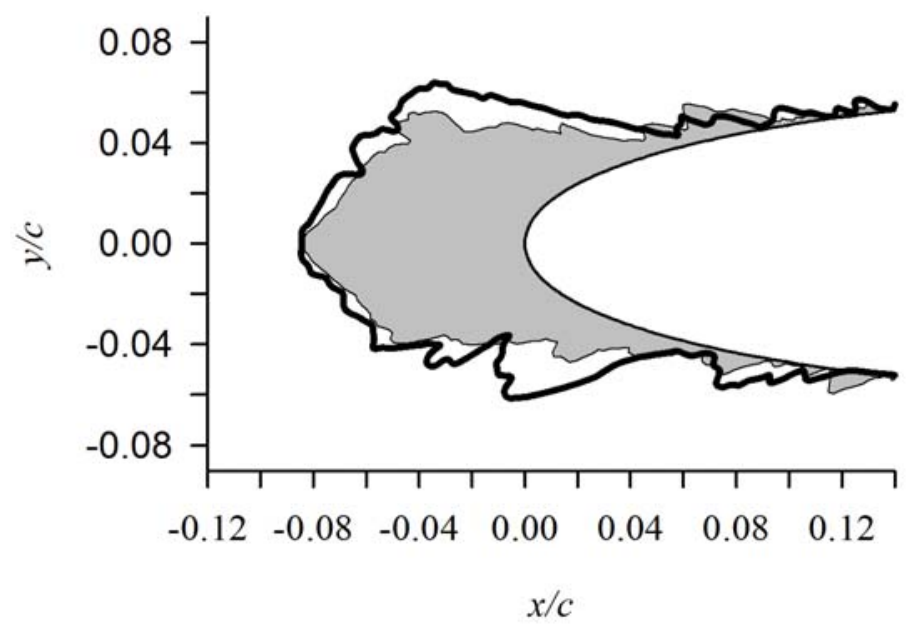

12-14-16/03, MCCS1, Ref 14

12-09-16/07, MCCS1, CWeL 14
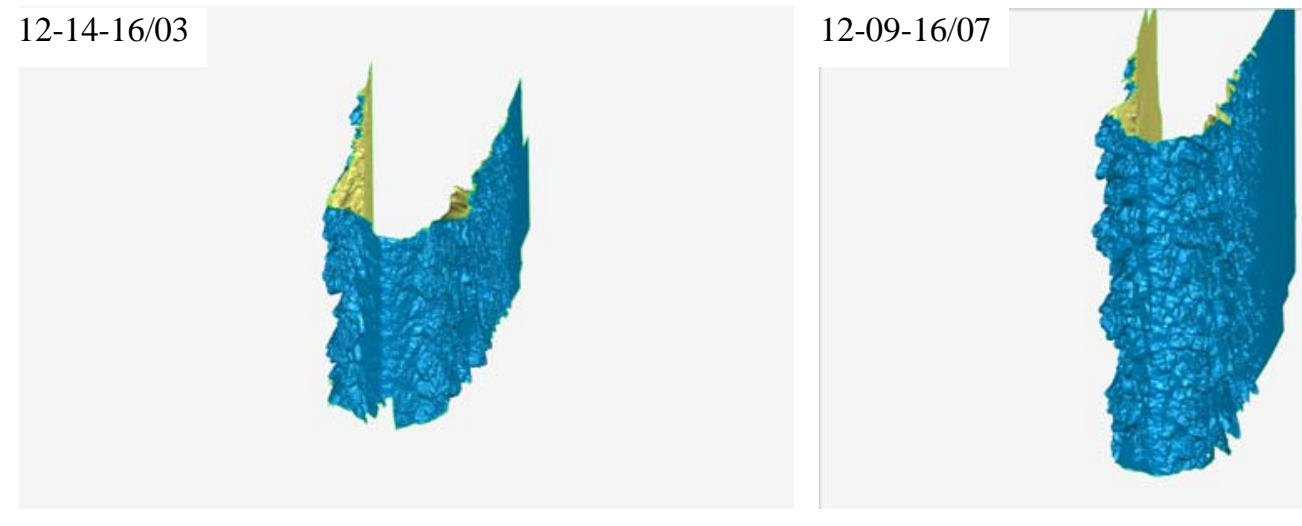

\begin{tabular}{ccccccccccc} 
Date/Run & $\begin{array}{c}c, \\
\text { in }\end{array}$ & $\begin{array}{c}\Lambda, \\
{ }^{\circ}\end{array}$ & $\begin{array}{c}t_{\text {tot }}, \\
{ }^{\circ} \mathrm{C}\end{array}$ & $\begin{array}{c}V, \\
\mathrm{kt}\end{array}$ & $\begin{array}{c}M V D, \\
\mu \mathrm{m}\end{array}$ & $\begin{array}{c}L W C, \\
\mathrm{~g} / \mathrm{m}^{3}\end{array}$ & $\begin{array}{c}\tau, \\
\mathrm{min}\end{array}$ & $\beta_{0} A_{c}$ & $n_{0}$ & $\begin{array}{c}W e_{L}, \\
10^{6}\end{array}$ \\
\hline $12-14-16 / 03$ & 36 & 30 & -16.8 & 150.0 & 93.0 & 0.50 & 45.2 & 3.17 & 1.00 & 2.65 \\
$12-09-16 / 07$ & 15 & 30 & -11.4 & 232.4 & 44.1 & 0.45 & 13.5 & 3.16 & 1.00 & 2.65
\end{tabular}

Figure 10 Reference and scale MCCS ice shape comparison. NACA 0012 models at $30^{\circ}$ sweep. $V_{\mathrm{R}}=150 \mathrm{kt}$; Rime ice structures were formed at $n_{0}=\mathbf{1 . 0}$.

\section{Summary and Concluding Remarks}

Two five-day icing tests were performed in NASA's Icing Research Tunnel to evaluate the current proposed scaling methods for swept wing ice shape scaling application. The preliminary results showed the scaling methods are effective. The MCCS ice shape profile and non-dimensional 3-D scan ice shape comparison evaluated in this study required further evaluation over wider airflow and icing cloud conditions as well as different model sizes to assess its applicability for swept-wing icing scaling analysis. 


\section{Acknowledgments}

This work is supported by the Advanced Aircraft Icing (AAI) subproject of the Advanced Air Transport Technology (AATT) Project in the NASA Advanced Air Vehicles Program, and is in response to the Airframe Icing Technical Challenge. The author wishes to thank Dr. Sam Lee of Vantage Partner, NASA Imaging Technology Center scientific imaging specialists Quentin Schwinn and Jordan Salkin for their ice shape imaging, scanning and post processing support of these tests and the IRT personnel for their continuing excellent technical support of the testing effort.

\section{References}

${ }^{1}$ Tsao, J. C. and Lee, S., “Evaluation of Icing Scaling on Swept NACA 0012 Airfoil Models,” NASA/CR-2012-217419, May 2012 and SAE-2011-38-0081, June 2011.

2 Title 14 Code of Federal Regulations, Chapter 1, Subchapter C, Part 25 Airworthiness Standards: Transport Category Airplanes, Appendix C; published by the Office of the Federal Register, National Archives and Records Administration, Washington, D.C., Amdt. 25-140, Effective 5-Jan-2015.

${ }^{3}$ Vargas, M., "Current Experimental Basis for Modeling Ice Accretions on Swept Wings", AIAA-2005-5188, June 2005.

${ }^{4}$ Vargas, M. and Tsao, J. C., "Observations on the Growth of Roughness Elements into Icing Feathers," AIAA-2007-0900, January 2007.

${ }^{5}$ Vargas, M., Tsao, J. C. and Rothmayer, A., "Review of Role of Icing Feathers in Ice Accretion Formation," SAE-2007-013294, September 2007.

${ }^{6}$ Vargas, M. and Tsao, J. C., "Time-Sequence Observations of the Formation of Ice Accretions on Swept Wings," AIAA2008-0470, January 2008.

${ }^{7}$ Lee, S., Broeren, A.P., Kreeger, R.E., Potapczuk, M.G. and Utt, L., "Implementation and Validation of 3-D Ice Accretion Measurement Methodology,” AIAA-2014-2613, June 2014.

${ }^{8}$ Ruff, G.A., “Analysis and Verification of the Icing Scaling Equations,” AEDC-TR-85-30, vol 1 (rev), March 1986.

${ }^{9}$ Anderson, D. N., "Manual of Scaling Methods,” NASA /CR-2004-212875, March 2004.

10 Anderson, D. N and Tsao, J. C., "Ice Shape Scaling for Aircraft in SLD Conditions,” NASA/CR-2008-215302 and DOT/FAA/AR-07/55, September 2008.

${ }^{11}$ Langmuir, Irving and Blodgett, Katharine B. “A Mathematical Investigation of Water Droplet Trajectories,” Army Air Forces Technical Report No. 5418, February 1946.

12 Abbott, Ira H. and von Doenhoff, Albert E., Theory of Wing Sections, Dover, New York, 1959, pp114 and 321.

13 Tsao, J. C. and Kreeger, R. E., "Experimental Evaluation of Stagnation Point Collection Efficiency of the NACA 0012 Swept Wing Tip,” AIAA-2009-4125 and NASA/TM-2010-216102, March 2010.

${ }^{14}$ Messinger, B.L., "Equilibrium Temperature of an Unheated Icing Surface as a Function of Airspeed,” J. Aeron. Sci., vol. 20 no. 1, January 1953, pp $29-42$.

15 Tribus, Myron, Young, G.B.W. and Boelter, L.M.K., “Analysis of Heat Transfer Over a Small Cylinder in Icing Conditions on Mount Washington,” Trans. ASME, vol. 70, November 1948, pp 971 - 976.

${ }^{16}$ Charpin, Francois and Fasso, Guy, "Essais de givrage dans la grande soufflerie de Modane sur maquettes a echelle grandeur et echelle reduite," L'Aeronautique et l'Astronautique, no. 38, 1972, pp 23 - 31. English translation published as "Icing Testing in the Large Modane Wind-Tunnel on Full-Scale and Reduced Scale Models,” NASA TM-75373, March 1979.

17 Reshotko, Eli and Beckwith, Ivan, "Compressible Laminar Boundary layer over a Yawed Infinite Cylinder with Heat Transfer and Arbitrary Prandtl Number,” NACA Rep. 1379, 1957.

${ }^{18}$ Bilanin, A. J., "Proposed Modifications to the Ice Accretion/Icing Scaling Theory,” AIAA-88-0203, January 1988.

${ }^{19}$ Olsen, W. and Walker, E., "Experimental Evidence for Modifying the Current Physical Model for Ice Accretion on Aircraft Surfaces,” NASA TM 87184, 1986.

${ }^{20}$ Hansman, R. John, Jr. and Turnock, Stephen, R., “Investigation of Surface Water Behavior During Glaze Ice Accretion,” $J$. Aircraft, vol. 26 no. 2, February 1989, pp 140-147.

21. Hansman, R. John, Jr. and Turnock, Stephen R., "Investigation of Microphysical Factors which Influence Surface Roughness During Glaze Ice Accretion,” $4^{\text {th }}$ International Workshop on Atmospheric Icing of Structures, Paris, September 1988.

22. Hansman, R.J., Breuer, K.S., Hazan, D., Reehorst, A. and Vargas, M., "Close-up Analysis of Aircraft Ice Accretion,” AIAA-93-0029, January 1993.

23. Bilanin, Alan J. and Anderson, David N., “Ice Accretion with Varying Surface Tension,” AIAA-95-0538 and NASA TM 106826, January 1995.

${ }^{24}$ Anderson, David N. and Tsao, J.C., “Additional Results of Ice-Accretion Scaling at SLD Conditions,” AIAA-2003-0390, January 2003 and NASA /CR-2005-213850, August 2005.

${ }^{25}$ Bartlett, C. Scott, “An Analytical Study of Icing Similitude for Aircraft Engine Testing,” DOT/FAA/CT-86/35 and AEDCTR-86-26, October 1986. 
${ }^{26}$ Bartlett, C. Scott, “Icing Scaling Considerations for Aircraft Engine Testing,” AIAA-88-0202, January 1988.

${ }^{27}$ Oleskiw, Myron M., De Gregorio, Fabrizio and Esposito, Biagio, “The Effect of Altitude on Icing Tunnel Airfoil Icing Simulation," Proceedings of the FAA International Conference on Aircraft Inflight Icing, DOT/FAA/AR-96/81,II, August 1996, pp $511-520$.

${ }^{28}$ Steen, L.E., Ide, R.F., Van Zante, J.F., and Acosta, W. J., “NASA Glenn Icing Research Tunnel: 2014 and 2015 Cloud Calibration Procedure and Results,” NASA/TM-2015-218758, May 2015.

${ }^{29}$ Van Zante, J.F., Ide, R.F., Steen, L.E., and Acosta, W.J., "NASA Glenn Icing Research Tunnel: 2014 Cloud Calibration Procedure and Results,” NASA/TM-2014-218392.

${ }^{30}$ Steen, Laura E., Ide, Robert F. and Van Zante, Judith F., “An Assessment of the SEA Multi-Element Sensor for Liquid Water Content Calibration of the NASA GRC Icing Research Tunnel,” Oral presentation, The SAE 2015 International Conference on Icing of Aircraft, Engines and Structures, 22-25 June 2015, Prague, the Czech Republic.

${ }^{31}$ Rigby, D.L., Struk, P.M., and Bidwell, C., "Simulation of fluid flow and collection efficiency for an SEA multi-element probe,” AIAA 2014-2752, June 2014.

32 http://www.geomagic.com

33 http://www.rhino3d.com

${ }^{34}$ Broeren, A.P., Potapczuk, M.G., Lee, S., Malone, A.M., Paul, B.P. and Woodard, B.S., "Ice-Accretion Test Results for Three Large-Scale Swept-Wing Models in the NASA Icing Research Tunnel,” AIAA-2016-3733, June 2016 and NASA/TM-2016-219137, September 2016. 